\title{
PROPUESTA PARA IMPLEMENTAREL PRESUPUESTO PLURIANUAL EN COSTA RICA COMO MEDIDA PARA GESTIONAR ADECUADAMENTE LAS FINANZAS PÚBLICAS
}

\author{
JENNIFER ISABEL ARROYO CHACÓN \\ Contraloría General de la República \\ prof.jenniferarroyo@yahoo.com
}

\section{RESUMEN}

El presente documento inicia describiendo la preocupación por la situación fiscal de Costa Rica señalada por organismos internacionales y nacionales, por ello se analiza el aporte del presupuesto público en la materia de finanzas públicas detallando la contabilidad presupuestaria y los clasificadores de ingresos y gastos que existen en esta materia en el país. En el tercer acápite se entra a analizar el presupuesto plurianual como un instrumento para la planificación macroeconómica describiendo la relación entre el presupuesto y la política económica, y definiendo la figura del prespuesto plurianual así como los beneficios que posee para la estabilidad de las finanzas públicas. Asimismo, se menciona algunos países latinoamericanos en los cuales se ha implementado esta forma de presupuestación que son: Uruguay, Colombia, Brasil, Chile, Paraguay, Perú y México. Como último apartado se estudia la propuesta realizada por la Contraloría General de la República para modificar el artículo 176 de la Constitución Política e introducir esta forma de presupuestación en el país. Concluye el documento que el presupuesto plurianual contribuye para la adecuada gestión de las finanzas públicas; no obstante, para lograrlo se requiere de otras acciones paralelas, de tal manera, que no se puede considerar que con solo la presupuestación plurianual se va alcanzar el equilibrio financiero que el país requiere actualmente.
PALABRAS CLAVE: PRESUPUESTO PLURIANUAL, PRESUPUESTO PÚBLICO, FINANZAS PÚBLICAS, DÉFICIT FISCAL.

\section{ABSTRACT}

This paper first describes the difficult fiscal situation of Costa Rica noted by international and national agencies, and how the public budget contributes to the administration of public funds. It continues by analyzing the multiannual budget as an instrument for macroeconomic planning, describing the relationship between the budget and economic policies, and defining the way multiannual budgets would benefit the stability of public finances. Some Latin American countries to have implemented this form of budgeting are Uruguay, Colombia, Brazil, Chile, Paraguay, Peru and Mexico. Finally, this document studies the proposal made by the General Comptroller of the Republic to amend Article 176 of the Constitution and to introduce this form of budgeting in our country. The paper concludes that the multi-annual budget contributes to the proper management of public finances; however, it is not the only element to achieve this objective; it is necessary to implement others actions.

KEYWORDS: MULTIANNUAL BUDGET, PUBLIC BUDGET, PUBLIC FINANCE, FISCAL DEFICIT. 


\section{INTRODUCCIÓN}

La finanzas públicas están pasando momentos de inestabilidad que ponen en juego el futuro del país, ello ha sido recalcado tanto por organismos nacionales: Contraloría General de la República y Banco Central de Costa Rica como por organismos internacionales: Fondo Monetario Internacional y calificadoras de riesgos, así como otros documentos que llaman la atención de esta problemática que cada día es mayor.

Los organismos internacionales han señalado como una de las principales causales para de inestabilidad de las economías es el divorcio entre planificación y presupuesto de largo plazo pues el presupuesto anual no permite visualizar situaciones futuras que podrían evitarse en el presente, al carecer de proyecciones a mediano y largo plazo.

Por lo tanto, se plantea la necesidad de implementar el presupuesto plurianual como un instrumento que le permitiría a los gobiernos preveer escenarios en el mediano y largo plazo. Dada la débil estabilidad de las finanzas públicas en el país, se propone la incorporación de la presupuestación plurianual y para ello, se requiere la reforma del artículo 176 Constitucional.

Este texto explica la presupuestación plurianual y los beneficios que posee para las finanzas públicas, y finalmente, analiza la propuesta concreta para incorporarla en el país.

\section{La situación fiscal en Costa Rica}

Los recientes informes emitidos por la Contraloría General de la República reflejan una preocupación por la estabilidad de las finanzas públicas y la necesidad de que el gobierno tome acciones para atender esta situación así evitar que llegue a niveles más inestables.

La memoria del año económico incluida en la Memoria Anual 2014 destaca que el déficit financiero del sector público alcanzó el 5.1\% del PIB, mientras que el déficit del sector público combinado llegó a los 5.9\% del PIB, textualmente dicho informe dice:

El déficit financiero del Sector Público alcanzó en 2014 la suma de $\$ 1.350$ mil millones (5,1\% del PIB), una magnitud similar a la de 2013, cuando significó 5,2\% del PIB, sin embargo, por encima del indicador de años anteriores (4,1\% en 2011 y 3,9\% en 2012). El Gobierno Central tiene un efecto predominante en este resultado, como ha sido lo usual, ya que alcanzó un déficit de ¿1.527 mil millones (5,7\% del PIB), mientras que otros subsectores institucionales como Gobiernos Locales, Órganos Desconcentrados e Instituciones Descentralizadas No Empresariales mantienen superávits, resultados que en buena parte provienen de las transferencias y cargas sociales que aporta el Gobierno Central. Cabe destacar que el Sector Público Combinado, que es objeto de la programación económica por parte del BCCR y agrega al déficit del Sector Público No Financiero las pérdidas del Banco Central de Costa Rica, asciende a un monto de $\$ 1.640$ mil millones en 2014, un 6,1\% del PIB frente a 5,9\% en 2013. (Contraloría General de la República, 2014, p. 138).

Igualmente en el informe Presupuestos Públicos 2015: Situación y Perspectivas se analiza el papel del nivel de endeudamiento del país y cómo el país fue calificado en forma negativa por la calificadora de riesgo por su incapacidad de reducir el déficit primario y el sostenido incremento en la deuda pública, sobre el particular dice:

Sobre este tema, cabe señalar que recientemente la calificadora de riesgo Fitch Ratings bajó la calificación de la deuda de Costa Rica, que pasó de perspectiva estable a negativa. Esta empresa señala entre sus consideraciones el continuo deterioro de las finanzas públicas, hasta alcanzar un déficit del Go- 
bierno de 5,6\% en 2014, el peor resultado desde 1980. Además, se apunta una baja recaudación fiscal debido a un bajo cumplimiento tributario y un sistema generalizado de incentivos y exenciones, así como una mayor rigidez del gasto desde 2008 cuando se dieron aumentos de la planilla del sector público y en las transferencias sociales. Fitch indica que la incapacidad para reducir el déficit primario y el incremento sostenido en la deuda pública podría manifestarse en una baja de la calificación, mientras que con una mayor confianza en la estrategia de consolidación fiscal que mejore las expectativas de estabilización de la deuda en el mediano plazo, podría retornar a una calificación estable. (Contraloría General de la República, 2015, p. 13)

Este nivel de endeudamiento también fue analizado por el Fondo Monetario Internacional (FMI) en el documento Staff Report for the 2014 Article IV Consultation en el donde destacó el creciente riesgo de Costa Rica ante el incremento de la deuda, al respecto dice:

The DSA [Debt Sustainability Analysis (DSA)] highlights Costa Rica's unsustainable debt dynamics. The debt stock is projected to rise to 51 percent of [Real Gross Domestic Product (GDP)] by 2019 under the baseline scenario, driven mostly by high fiscal deficits. There are substantial upside risks to the projected debt path from plausible macro shocks. Risks from relatively high financing needs are somewhat mitigated by the existence of a stable domestic investor base ${ }^{1}$ (International Monetary Fund, 2015, p. 51)

1 Traducción propia. El DSA [Análisis de Sostenibilidad de Deuda (DSA)] destaca la dinámica insostenible de la deuda de Costa Rica. El saldo de la deuda se prevé que aumente al 51 por ciento del PIB en 2019 bajo el escenario base, impulsado principalmente por los altos défcits fiscales. Existen riesgos al alza sustanciales a la trayectoria de la deuda proyectada de los choques macro plausibles. Los riesgos de las necesidades de financiamiento relativamente altos Están algo mitigados por la existencia de una base de inversores nacionales estables.
Los principales hallazgos respecto a la situación fiscal del país se pueden sintetizar en los siguientes puntos:

- Tendencia de déficit promedio financiero de $4,6 \%$ PIB $(5,7 \%$ en 2014)

- Déficit primario supera el 3\% PIB

- Carga tributaria pasa de 15,3\% en 2008 a $13,2 \%$ en 2014

- Gasto total (sin amortización) pasa en últimos seis años de 12\% a más del 19\% del PIB

- Gasto corriente es 74\% del total de gasto en 2014 (65\% en 2013)

- Gasto de capital ha venido disminuyendo hasta llegar a un 6\% en 2013 aproximadamente

- Transferencias del Gobierno Central al resto del Sector Público pasan de 2,75\% a 4,81\% del PIB en 2008 a 2014

- Gobierno Central ha incrementado su deuda hasta alcanzar niveles cercanos al 40\% del PIB

- Deuda del sector público se aproxima al $60 \%$ del PIB

Asimismo, cada uno de los sectores del ámbito público presenta distintas situaciones de inestabilidad financiera (ver Figura 1).

Las previsiones dadas por el órgano contralor para el año 2015 distan mucho de ser alentadoras con un proyección de un déficit para el Gobierno Central del $5.7 \%$ del PIB que suponen un déficit del 6.9\% siendo urgente una mejor gestión de las finanzas públicas.

En 2015 se proyecta el déficit para el Gobierno Central en el valor 5,7\% del PIB, de acuerdo con la programación macroeconómica 
FIGURA 1

SITUACIONES DE INESTABILIDAD FINANCIERA

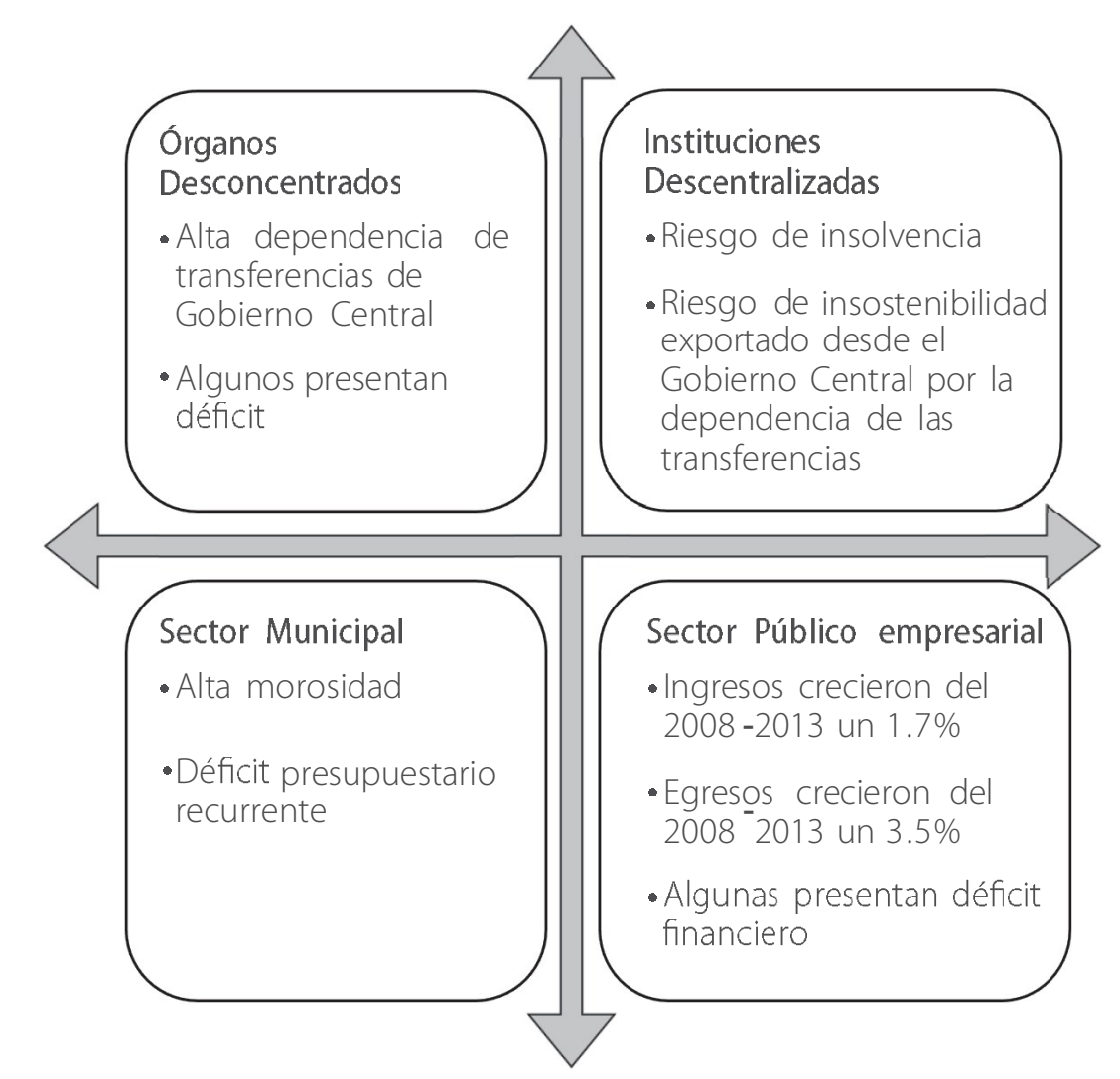

Fuente: Elaboración propia con base en la bibliografía consultada

del BCCR, aunque las cifras incluidas en el presupuesto suponen un déficit de 6,9\%. Por lo tanto, una subejecución notable del gasto, o un aumento importante de los ingresos, serán necesarios para lograr la proyección del programa En 2015 se proyecta el déficit para el Gobierno Central en el valor 5,7\% del PIB, de acuerdo con la programación macroeconómica del BCCR, aunque las cifras incluidas en el presupuesto suponen un déficit de $6,9 \%$. Por lo tanto, una subejecución notable del gasto, o un aumento importante de los ingresos, serán necesarios para lograr la proyección del programa. (Contraloría General de la República, 2015, p. 139)
Tanto los organismos nacionales como internacionales han llamado la atención del gobierno costarricense sobre el riesgo que corren las finanzas públicas, el gasto público, el incremento en la deuda pública, la crisis fiscal, el estancamiento de la producción y otros factores que inciden de manera negativa en la estabilidad económica del país.

Si bien, el Ministerio de Hacienda ha tomado acciones para mejorar la recaudación de tributos el país requiere acciones más contundentes y medidas más eficientes; al respecto se recomienda: poner límites a la discrecionalidad, potenciar la capacidad de gestión y evaluación por resultados y el restablecimiento gradual de condiciones financieras; asimismo de gran relevancia se 
destaca el tema de la planificación y presupuestación por la importancia que posee el presupuesto público en la economía nacional, aspecto que se analizará en un acápite siguiente.

\section{El presupuesto público en las finanzas públicas}

\section{Concepto de presupuesto público}

El presupuesto público se puede definir como un instrumento financiero mediante el cual las instituciones públicas registran los ingresos y gastos necesarios para que la institución ejecute sus proyectos y alcance sus metas y objetivos, satisfacción así el servicio público para la cual creada.

Las normas técnicas sobre presupuestos públicos emitidas por la Contraloría General de la República lo definen como: "Instrumento que expresa en términos financieros el plan anual de la institución, mediante la estimación de los ingresos y de los gastos necesarios para alcanzar los objetivos y las metas de los programas presupuestarios establecidos."

La Ley de la Administración Financiera y Presupuestos Públicos establece que el Sistema de Administración Financiera está integrado por el Subsistema de Presupuesto, y define este último en el numeral 30 de la siguiente manera: "El Subsistema de Presupuesto comprende los principios, las técnicas, los métodos y procedimientos empleados, así como los órganos participantes en el proceso presupuestario." (Asamblea Legislativa de Costa Rica, 2001).

Las normas técnicas de presupuesto público establecen que el Subsistema de Presupuesto Institucional formará parte del Sistema de Administración Financiera Institucional y comprende los principios, las técnicas, los métodos y procedimientos empleados, así como los órganos participantes en el proceso presupuestario institucional.

El subsistema del Presupuesto Institucional deberá estar orientado a alcanzar los siguientes objetivos:

a) Presupuestar los recursos según el contexto macroeconómico, relacionado con la función pública que realiza la institución, de modo que el presupuesto refleje las prioridades y actividades estratégicas consideradas en los planes institucionales, así como los objetivos y metas de los planes de desarrollo nacionales, sectoriales, regionales y municipales, según corresponda y de acuerdo con el ordenamiento jurídico aplicable.

b) Lograr que el proceso presupuestario, en cada una de sus fases, se cumpla en el tiempo y la forma requeridos.

c) Velar porque la ejecución presupuestaria se programe y desarrolle coordinadamente, utilizándolos recursos según las posibilidades finarcieras, la naturaleza de los gastos y los avances en el cumplimiento de los objetivos y metas.

\section{La contabilidad presupuestaria en Costa Rica}

a. Contabilidad presupuestaria

Un elemento fundamental del presupuesto es la contabilidad presupuestaria, es decir, las cuentas con las cuales se elabora el presupuesto y posteriormente se realiza el registro contable y la liquidación presupuestaria.

La contabilidad presupuestaria se define como: "Es una rama de la contabilidad que tiene por objeto resumir de forma sistemática las provisiones de gastos proyectados y las estimaciones de ingresos previstas para atenderlos; a fin de que sirva como instrumento de control, de mejora de la gestión, de estabilidad y de asignación efciente de los recursos." (Arroyo Chacón \& Bolaños González, Derecho Empresarial II, 2012, p. 186) 
La contabilidad presupuestaria se basa en tres principios fundamentales que son:

Principio de especificación: El presupuesto, en materia de ingresos, debe señalar con precisión sus fuentes y su clasificación y, en lo que a gastos se refiere, las características y clasificación de los bienes y servicios

Principio de claridad: El documento que contiene el presupuesto sin omitir las reglas técnicas esenciales, debe ser comprensible para los diferentes usuarios

Principio de especialidad cuantitativa y cualitativa: Las asignaciones presupuestarias del presupuesto de gastos, con los niveles de detalle aprobados, constituirán el límite máximo de autorizaciones para gastar. No podrán adquirirse compromisos para los cuales no existan saldos presupuestarios disponibles. Tampoco podrán destinarse saldos presupuestarios a una finalidad distinta de la prevista en el presupuesto, de conformidad con los preceptos legales y reglamentarios

Asimismo, con el fin de darle uniformidad a los conceptos, contar con un único criterio para el registro y una interpretación y análisis adecuada de la información contable se crearon los clasificadores, tanto de ingresos y gastos.

b. Clasificador de ingresos

El clasificador de ingresos agrupa los ingresos de las entidades en categorías homogéneas según la naturaleza y las transacciones que los originan, ello con el fin de:

- Uniformar criterios de clasificación y presentación

- Orienta programación, análisis y seguimiento de gestión económica y financiera

- Homogenizar información de finanzas públicas

- Elaboración de estadísticas, indicadores, etc.

En detalle cada una de estas cuentas se definen por el clasificador del gasto presupuestario como:

Ingresos corrientes: se originan en las transacciones corrientes que realizan las entidades del sector público destinadas a incrementar el patrimonio neto. Algunos provienen de la potestad tributaria del Gobierno de la República, son de carácter obligatorio y se caracterizan por no guardar proporción con el costo de los servicios

FIGURA 2

\section{CATEGORÍAS DE INGRESOS}

\begin{tabular}{|c|c|c|c|c|c|}
\hline 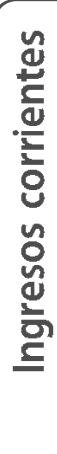 & $\begin{array}{l}\text { Ingresos } \\
\text { tributarios } \\
\text { Contribuciones } \\
\text { sociales } \\
\text { Ingresos no } \\
\text { tributarios } \\
\text { Transferencias } \\
\text { corrientes }\end{array}$ & 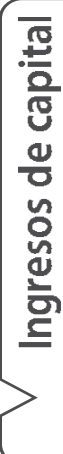 & $\begin{array}{l}\text { Venta de activos } \\
\text { Recuperación y } \\
\text { anticipos por obra } \\
\text { de utilidad pública } \\
\text { Recuperación de } \\
\text { prestamos } \\
\text { Transferencias de } \\
\text { capital } \\
\text { Otros ingresos de } \\
\text { capital }\end{array}$ & & $\begin{array}{l}\text { Financiamiento } \\
\text { interno } \\
\text { Financiamiento } \\
\text { externo } \\
\text { Recursos de } \\
\text { vigencias } \\
\text { anteriores } \\
\text { Recursos de } \\
\text { emisión } \\
\text { monetaria }\end{array}$ \\
\hline
\end{tabular}

Fuente: Elaboración propia con base en los clasificadores de ingresos del Ministerio de Hacienda. 
prestados. Otros provienen de la venta de bienes y servicios, por el cobro derechos administrativos y rentas asociadas a la propiedad de factores productivos

Contribuciones sociales: son obligaciones a cargo de empleadores, empleados, trabajadores independientes, pensionados y del Estado, de carácter obligatorio o voluntario, para atender los distintos regímenes de previsión, desarrollo y asistencia social

Ingresos no tributarios: ingresos que percibe el Estado y sus instituciones, provenientes de la prestación de servicios, venta de bienes, concesión de licencias y permisos, rentas derivadas de la actividad empresarial pública y de su propio patrimonio; que no constituyen una fuente de ingresos impositivos. Incluye la venta de bienes y servicios, ingresos de la propiedad, derechos administrativos, multas, sanciones, remates y confiscaciones, intereses moratorios y otros ingresos no tributarios

Transferencias corrientes: ingresos recibidos de personas, entes y órganos del sector público, privado y externo para financiar gastos corrientes con el fin de satisfacer necesidades públicas de diversa índole, sin que medie una contraprestación de bienes, servicios o derechos a favor de quien traslada los recursos. Estas transferencias corrientes incluyen las especificadas y autorizadas por ley, las voluntarias, los subsidios, subvenciones y por medio de donaciones

Ingresos de capital: ingresos del Sector Público constituidos por fondos, bienes o recaudaciones que producen modificaciones en la situación patrimonial de las Instituciones Públicas mediante la disminución del activo. Incluye los ingresos por la venta de activos tangibles e intangibles, recuperación de anticipos por obras de utilidad pública, los reembolsos por préstamo concedidos, las transferencias de capital y otros recursos de capital
Transferencias corrientes: ingresos recibidos de personas, entes y órganos del sector público, privado y externo para financiar gastos corrientes con el fin de satisfacer necesidades públicas de diversa índole, sin que medie una contraprestación de bienes, servicios o derechos a favor de quien traslada los recursos. Estas transferencias corrientes incluyen las especificadas y autorizadas por ley, las voluntarias, los subsidios, subvenciones y por medio de donaciones.

Venta de activos: comprende los ingresos por la venta de los activos fjos e intangibles

Recuperación y anticipos por obra de utilidad pública: ingresos recibidos de la recuperación de las inversiones efectuadas en obras de utilidad pública. Incluye la recuperación y aportes de recursos para construcciones públicas como aceras, acueductos, alcantarillados pluvial y sanitario, asfaltado de calles, construcción y mantenimiento de vías de comunicación, cordones de caño, instalaciones eléctricas, rupturas de calles, oleoductos y poliductos y otras obras de utilidad pública, que vienen a financiar parcial o tota mente la obra.

Recuperación de préstamos: incluye los ingresos por la recuperación de préstamos concedidos al Sector Público, Sector Privado y Sector Externo.

Transferencias de capital: ingresos recibidos de personas, entes y órganos del sector público, privado y externo para financiar gastos de capital con el fin de satisfacer necesidades públicas de diversa índole, sin que medie una contraprestación de bienes, servicios o derechos a favor de quien traslada los recursos. Estas transferencias de capital incluyen las especificadas y autorizadas por ley, las voluntarias, los subsidios y subvenciones

Financiamiento: recursos que tienen el propósito de cubrir las necesidades derivadas de la insuficiencia de los ingresos corrientes y de capital, mediante la adquisición de cuentas de pasivo por 
la utilización de créditos y colocación de títulos valores internos y externos, además incluye la incorporación de superávit y recursos de emisión:

- Financiamiento interno

- Financiamiento externo

- Recursos de vigencias anteriores

- Recursos de emisión monetaria

- Herramienta de gestión financiera

- Utilizada en las etapas del proceso presupuestario

- Conjunto de cuentas ordenadas y agrupadas según naturaleza de bien o servicio

c. Clasificador de gastos

Por otra parte se cuenta con clasificador del gasto público que es el conjunto de cuentas de gasto, ordenadas y agrupadas de acuerdo con la naturaleza del bien o servicio que se está adquiriendo - la operación financiera que se esté efectuando, este clasificador cumple los siguientes objetivos:

- Facilita cumplimiento del principio de especialidad cualitativa y cuantitativa

- Información para programar adquisición de bienes y servicios para lograr propósitos

- Control y disposición del inventario

- Información para toma de decisiones de política económica y presupuestaria.

A continuación se explicarán las principales cuentas que componen esta clasificación:

Gastos corrientes: comprende las erogaciones no recuperables que se destinan a la remuneración de los factores productivos, adquisición de bienes y servicios y transferencias, para atender las actividades ordinarias de producción de bienes y prestación de servicios que son propias del sector público. Los bienes y servicios clasificados en esta partida tienen una vida prevista inferior a un año, por lo que no forman parte de los bienes duraderos. Comprende los gastos de consumo, intereses y transferencias corrientes:

Gastos de consumo: son los gastos en que incurren las instituciones del Sector Público, como resultado del desarrollo directo de la operación básica o cometido estatal en su actividad de servicio a la comunidad mediante el suministro de bienes y servicios. Incluye los gastos en que incurren las empresas públicas en la producción y comercialización de bienes y servicios. Estos gastos comprenden las remuneraciones al personal y la adquisición de bienes y servicios.

Intereses: comprende los gastos que reflejan el costo de utilizar el capital financiero recibido y de otras deudas asumidas. Estos gastos se destinan al pago de intereses por concepto de títulos valores emitidos, préstamos adquiridos y otras obligaciones.

Transferencias corrientes: erogaciones que se destinan a satisfacer necesidades públicas de diversa índole, sin que exista una contraprestación de bienes, servicios o derechos a favor de quien transfiere los recursos los cuales se destinan a, personas, entes y órganos del sector público, privado y externo para financiar fundamentalmente gastos corrientes por concepto de donaciones, subsidios, subvenciones, cuotas organismos internacionales, prestaciones, pensiones, becas, indemnizaciones entre otros.

Remuneraciones: remuneraciones básicas en dinero al personal permanente y transitorio de la institución cuya relación se rige por las leyes laborales vigentes. Además, comprende los incentivos derivados del salario o complementarios a este, como el decimotercer mes o la retribución por años servidos, así como gastos por concepto de dietas, las contribuciones patronales al desarrollo y la seguridad social y gastos de representación personal. 


\section{FIGURA 3 \\ PRINCIPALES CATEGORÍAS DE GASTOS}

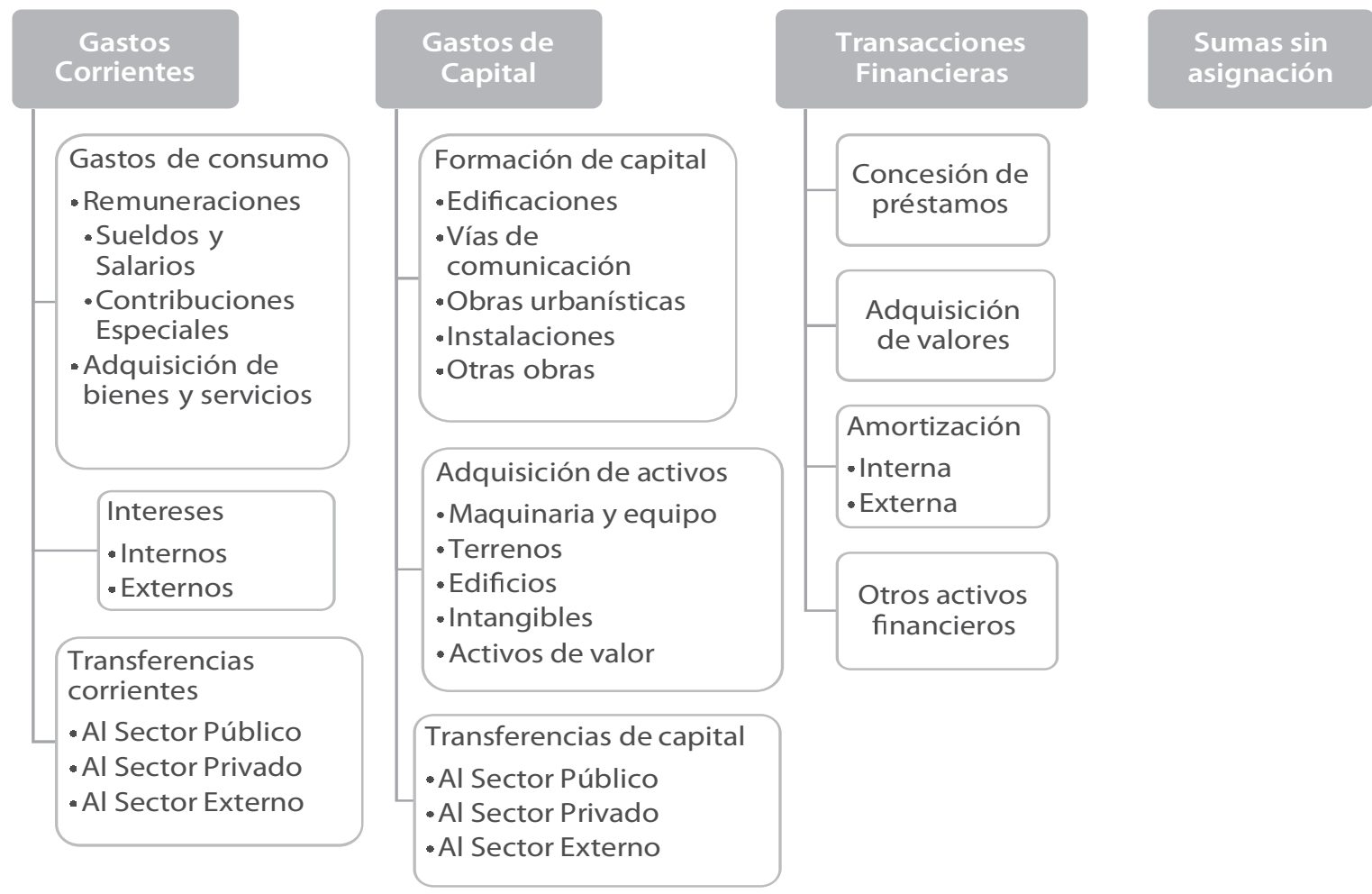

Fuente: Elaboración propia con base en los clasificadores del gasto del Ministerio de Hacienda.

Intereses y comisiones: esta partida comprende las erogaciones destinadas por las instituciones públicas para cubrir el pago a favor de terceras personas, por la utilización en un determinado plazo de recursos financieros provenientes de los conceptos de emisión y colocación de títulos valores, contratación de préstamos directos, créditos de proveedores, depósitos a plazo y a la vista, avales asumidos, entre otros pasivos de la entidad, transados en el país o en el exterior.

Servicios: obligaciones que la institución contrae, generalmente, mediante contratos administrativos con personas físicas o jurídicas, públicas o privadas, por la prestación de servicios de diversa naturaleza y por el uso de bienes muebles e inmuebles, incluyendo los servicios que se destinan al mantenimiento, conservación y reparación menor $u$ ordinaria, preventiva y habitual de bienes de capital, que tienen como finalidad conservar el activo en condiciones normales de servicio.

Materiales y suministros: en esta partida se incluyen los útiles, materiales, artículos y suministros que tienen como característica principal su corta durabilidad, pues se estima que se consumirá en el lapso de un año. Sin embargo, por conveniencia se incluyen algunos de mayor durabilidad, en razón de su bajo costo y de las dificultades que implicaría un control de inventario. Comprende los materiales y suministros que se aplican en la formación de bienes de capital mediante el mecanismo de construcción por Administración. También 
los artículos y suministros que se destinan al mantenimiento y reparación de bienes del activo fijo.

Activos financieros: erogaciones destinadas a la concesión de préstamos y la adquisición de valores de largo plazo con vigencia de un año o más, tales como bonos, acciones, certificados de inversión, certificados de depósitos a plazo, títulos de propiedad, certificados de participación hipotecaria y otros instrumentos financieros, así como los créditos concedidos en calidad de proveedores.

Bienes duraderos: omprende la adquisición de bienes duraderos nuevos o ya existentes, como son los bienes de capital fijo, muebles e inmuebles. Incluye los procesos de construcción, así como la adición, y mejoramiento de bienes de capital, diferenciándose de aquellos procesos que tienen como propósito el mantenimiento normal de dichos bienes, menor o habitual. Incluye también los costos por obras complementarias y otros trabajos asociados con las construcciones, adiciones y mejoras tales como: demolición, señalización, demarcación, movimientos de tierras y otras obras. Incluye los costos asociados a la adquisición de la propiedad de la tierra, edificios y otros bienes de capital fijo y activos intangibles.

Transferencias de capital: aportes que la Institución otorga a personas, entes y órganos del sector público, privado y externo para financiar gastos de capital con el propósito de satisfacer diversas necesidades públicas, sin que exista contraprestación de bienes, servicios o derechos a favor de los organismos que realizan el aporte. Dichas transferencias deben regirse por la normativa jurídica respectiva.

Gastos de capital: comprende las erogaciones no recuperables para la adquisición o producción de bienes duraderos, destinados a un uso intensivo en el proceso de producción durante un largo período de tiempo. Estos gastos implican aumentos en los activos, mejoras en los ya existentes y la prolongación de su vida útil, a fin de incrementar la capacidad productiva o de servicio de las instituciones públicas. Incluye los gastos por concepto de remuneraciones, compra de bienes y servicios asociados a la formación de capital, así como las transferencias de capital. En esta categoría se incluye: Formación de capital, adquisición de activos y transferencias de capital.

Formación de capital: erogaciones destinadas a la producción de bienes de capital, con la característica de que no se agotan durante su primer uso, tienen una vida útil superior a un año, están sujetos a depreciación y a inventario como activo fijo. Incluye los gastos por concepto de remuneraciones, adquisición de bienes y servicios utilizados en la producción de bienes de capital, realizados por administración, así como los contratados con terceros. Comprende las adiciones y mejoras a los bienes de capital, diferenciándolos de aquellos procesos que tienen como propósito el mantenimiento normal de dichos bienes. Incluye la construcción de edificios, instalaciones, obras viales, urbanísticas y otras obras.

Adquisición de activos: erogaciones destinadas a la adquisición de bienes de capital, que poseen una vida útil superior a un año, están sujetos a inventario como activo fijo, son objeto de depreciación, a excepción de los terrenos, intangibles y otros activos de valor. Incluye la adquisición de maquinaria y equipo utilizados en la producción de otros bienes y servicios, de edificios, la compra de terrenos, los activos intangibles y los activos de valor.

Transferencias de capital: erogaciones que se destinan a personas, entes y órganos del sector público, privado y externo, con el objeto de que los beneficiarios puedan adquirir y producir activos de capital, compensarlos por daños o destrucción de los mismos o aumentar su capital financiero, sin que exista contraprestación de bienes, servicios o derechos a favor de los organismos públicos que realizan el aporte. 
Transacciones financieras: son erogaciones generadas por transacciones recuperables, que se originan en el incremento de los activos financieros y la disminución de los pasivos. En este grupo se reflejan diversos tipos de transacciones o aplicaciones como son la concesión de préstamos, la adquisición de valores, la amortización de la deuda y otros activos financieros.

Concesión de préstamos: erogaciones destinadas a la actividad crediticia mediante las cuales se entrega a un prestatario una suma de dinero, bienes u otro medio convenido, para su utilización durante un determinado plazo, con la condición de devolverla al final del mismo y con el reconocimiento de una tasa de interés pactada, concedidos a entes públicos, sector privado y sector externo.

Adquisición de valores: erogaciones destinadas a la adquisición de documentos o títulos emitidos legítimamente, por los cuales se exterioriza el derecho sobre un determinado crédito o valor adeudado por terceros, tales como bonos, títulos de la deuda pública, certificados de inversión, certificados de depósito y otros.

Amortización: erogaciones por concepto de reembolsos mediante pagos parciales o totales a entes públicos, privados o externos por concepto de obligaciones formalmente adquiridas o asumidas, producto de la colocación de títulos valores, préstamos recibidos y otras obligaciones.

Otros activos Financieros: erogaciones destinadas al aporte de capital en empresas públicas o privadas, para constituir o fortalecer el capital social, así como a otros activos financieros no considerados en los conceptos anteriores.

Sumas sin asignación: comprende las cuentas del grupo "sumas sin asignación presupuestaria" del Clasificador Objeto del Gasto, que permiten guardar el equilibrio presupuestario.
La clasificación es aún más detallada pero estas principales cuentas nos permiten entender las dimensiones que abarca y cubre el presupuesto público y de allí su relación con la política económica del país.

\section{El presupuesto plurianual como un instrumento para la planificación macroeconómica}

\section{Sobre la relación entre el presupuesto y la política económica}

En sus orígenes el presupuesto público cumplía una función de planificación y control; no obstante, con la complejidad de las finanzas públicas actuales a esa labor este instrumento ha adquirido una gran relevancia para efectos de política económica. En rol de ordenación de la actividad económica financiera cumple tres objetivos:

- Ofrecer a los agentes económicos previsiones de calidad para la toma de sus decisiones.

- Ser un medio transparente de rendición de cuentas y de exigencia de responsabilidades

- Asegurar la consistencia de los ingresos y gastos públicos con las variables macroeconómicas básicas a medio y largo plazo y con los objetivos generales de la política económica.

Nótese su importante papel en la política económica, tanto en su dimensión microeconómica, como en la macroeconómica, de tal forma que es un instrumento para contrarrestar las oscilaciones de los ciclos económicos y para el impulsar el crecimiento y la creación de empleo.

Por tanto, este marco de interacción permanente entre economía nacional, política económica y presupuesto público, constituye un elemento 
esencial para el diseño y programación de las políticas públicas, en doble sentido: la situación económica nacional condiciona la orientación de la política económica por un lado, y por el otro, los objetivos y medidas de la política económica que se instrumentan a través del presupuesto tienen una incidencia fundamental en el comportamiento de la economía.

En consecuencia, no podemos concebir el presupuesto público desde una visión estática como una previsión de ingresos y gastos para un determinado ejercicio económico, sino que el presupuesto debe integrar objetivos cuyo alcance requieren varios ejercicios económicos. Resaltando igualmente su flexibilidad, lo cual implica:

- Debe responder en cada momento a la coyuntura económica y social, lo cual puede condicionar y reorientar, bien los objetivos a alcanzar, o bien los medios para alcanzarlos

- Debe tener en cuenta las prioridades expresadas por la sociedad, lo que igualmente puede conducir a una revisión de los objetivos de las políticas públicas.

- Debe adaptarse a los condicionantes de organización y gestión de la administración pública, desde la perspectiva de perseguir siempre una gestión eficaz y eficiente de los recursos públicos.

De tal manera que la concepción actual de presupuesto público implica tres facetas que se observan en la Figura 4.

Dada la importantísima relación existente entre política económica y política fiscal, podemos considerar que únicamente existe un sólo escenario: macroeconómico y presupuestario, ya que un escenario macroeconómico para reflejar adecuadamente la realidad económica, debe contener también las variables concernientes al comportamiento e influencia del sector público en la economía.

Por lo tanto podemos definir el escenario macroeconómico y presupuestario como el marco normativo y previsional a medio plazo que integra, de forma consistente y dinámica, la interacción entre las variables principales de la economía y los objetivos y orientación de la política económica general y de la presupuestaria en particular. Es normativo porque contiene objetivos, prioridades y criterios definidos por el gobierno y previsional porque integra una previsión razonable de las principales magnitudes económicas.

El escenario macroeconómico y presupuestario describe los principales objetivos de la política económica a mediano plazo y proporciona el marco de evolución de las principales magnitudes macroeconómicas que conforman la actividad general de la economía: Producción y demanda, precios y rentas, mercado laboral, sector externo y sector público. Se puede definir como:

El escenario macroeconómico y presupuestario es el instrumento previsional y de situación que nos permite reflejar la evolución previsional y de situación que nos permite reflejar la evolución de las principales magnitudes macroeconómicas, abarcando todas las áreas de una economía, los objetivos de la política económica y los efectos de las estrategias y medidas puestas en marcha para conseguirlos.

Su elaboración se fundamenta en la obtención de datos de una pluralidad de fuentes, seleccionadas fundamentalmente, en función de su grado de especialización y confiabilidad.

El proceso no se agota en sí mismo, sino que antes al contrario, es objeto de una continua retroalimentación, de forma que se puedan 
FIGURA 4

\section{FACETAS DEL PRESUPUESTO PÚBLICO}

\begin{tabular}{|c|c|c|}
\hline Instrumento de política económica & Instrumento de programación & Instrumento de negociación \\
\hline $\begin{array}{l}\text { El presupuesto ha dejado de ser un instrumento } \\
\text { de planificación y control para convertirse en un } \\
\text { elemento esencial para el diseño y programación } \\
\text { de las políticas públicas dada la interacción perma- } \\
\text { nente entre economía nacional, política económica } \\
\text { y presupuesto público }\end{array}$ & $\begin{array}{l}\text { La evolución de la técnica presupues taria ha } \\
\text { significado también un desplazamiento desde } \\
\text { los recursos utilizados hasta los objetivos que se } \\
\text { pretenden conseguir con unos recursos limitados, } \\
\text { lo que implica configurar al presupuesto como un } \\
\text { instrumento de gestión directa, de asignación de } \\
\text { los recursos y de ordenación de las políticas de } \\
\text { gasto, en el marco de una programación racional } \\
\text { de la actividad pública en el medio plazo. }\end{array}$ & $\begin{array}{l}\text { Desde una perspectiva de procedimiento, el } \\
\text { presupuesto es el resultado de un complejo } \\
\text { proceso de negociaciones, en el que confluye } \\
\text { una multiplicidad de intereses de carácter polí- } \\
\text { tico, social y económico, tanto externos, como } \\
\text { internos a la propia Administración Pública. } \\
\text { Ello asimismo, se traduce en la participación de } \\
\text { un gran número de agentes en el proceso, que } \\
\text { compiten por diferenciar y priorizar sus propios } \\
\text { programas en la asignación de los recursos. }\end{array}$ \\
\hline
\end{tabular}

incorporar las variaciones que se vayan produciendo en las magnitudes contenidas en el escenario, así como, en su caso, el replanteamiento de las medidas de política económica adoptadas. (Quintana \& Palancar Valera, 2012, p. 30)

Proporciona el marco de evolución de las principales magnitudes macroeconómicas que conforman la actividad general de la economía de un país y describe los principales objetivos de la política económica a medio plazo; asimismo, su formulación permitirá realizar un diagnóstico de la realidad económica para destacar sus principales problemas o puntos débiles, adoptar decisiones y determinar los planteamientos de acción necesarios para hacer frente a los problemas y retos planteados $y$, por tanto, diseñar la orientación y principales medidas de política económica y realiza proyecciones a medio plazo de las principales variables macroeconómicas que recojan evoluciones de dichas variables a partir, por un lado, de un análisis tendencial alimentado por el comportamiento pasado y situación actual de la economía, tanto a nivel nacional como internacional y, por otro, de la influencia de las decisiones, estrategias y medidas de política económica que se hayan emprendido.

El escenario macroeconómico se elabora normalmente con modelos econométricos de simulación que se fundamentan en la evaluación y proyección de tendencias: comportamiento pasado y situación actual; además, teniendo en cuenta la situación nacional, internacional, decisiones políticas y los criterios y previsiones de expertos independientes.

La programación presupuestaria plurianual posee dos fases diferenciadas: Una de carácter general que podemos denominar "macro", en la cual el papel predominante corresponde a las autoridades del área estrictamente económica dentro del gobierno, y otra de desarrollo o "micro", en la cual es necesario que tomen parte activa también las restantes autoridades con responsabilidad en otras áreas, es decir, la participación de los gestores del gasto.

\section{Concepto de Presupuesto Plurianual}

El presupuesto plurianual se concibe como un instrumento al servicio de la eficiencia en la asignación y utilización de los recursos públicos, cuya 
necesidad resulta acentuada por la triple función que, desde una perspectiva económica, están llamados a cumplir los presupuestos.

Se puede definir como un instrumento de la alta gerencia pública, que contiene la distribución entre las instituciones públicas y hasta un cierto nivel de detalle, de los recursos financieros del Estado que se prevén recaudar en un período mayor al año, por lo general de tres a cinco años, con sujeción al plan estratégico del gobierno y al marco fiscal de mediano plazo.

Las estimaciones plurianuales de los ingresos, gastos y financiamiento distribuidos instituciona mente son parte de los componentes principales de este instrumento, así como las proyecciones de mediano plazo del producto interno bruto y el marco fiscal del gobierno. También concebido en forma integral, contiene previsiones de las variables físicas, que derivan de las prioridades y resultados estratégicos que se desprenden del plan de gobierno para período plurianual, acotado por las disponibilidades financieras. Se compone de tres grandes elementos que me muestran en la figura 5.

Los elementos de la Figura 5 del presupuesto se explican de la siguiente manera:

El presupuesto plurianual de ingresos: previsión de la recaudación tendencial de los ingresos públicos vinculada a tres aspectos fundamentales: la evolución esperada en la actividad económica general, las modificaciones previstas en la normativa tributaria y las mejoras en la gestión tributaria y la lucha contra el fraude. Se diseña con el objeto de prever el volumen de ingresos que nos permitirá alcanzar de determinados objetivos de índole fiscal, los cuales pueden ser: Lograr mantener un determinado nivel de déficit o superávit, atender un volumen de gasto público dado, dentro de la restricción impuesta por un objetivo de déficit o superávit.
El presupuesto plurianual de gastos: es el instrumento en el cual una unidad económica plasma sus previsiones de gastos para el medio plazo. Podríamos definir la política de gasto como una agrupación de programas de gasto o de partes de programas de gasto, con la característica de presentar objetivos comunes.

Modelos de consistencia: por análisis de consistencia entendemos la correlación entre los escenarios de ingresos y gastos y el escenario macroeconómico. La correlación entre los escenarios de ingresos y gastos permite generar las envolventes financieras, principalmente el déficit público, que constituyen el marco para analizar su consistencia con el escenario macroeconómico. Sería por lo tanto, el elemento de cierre del escenario macroeconómico y presupuestario, que puede conducir, bien a modificar los objetivos o la tendencia de evolución de las variables del escenario macroeconómico, bien a alterar el marco de objetivos o prioridades del escenario presupuestario a medio plazo. El análisis de consistencia permitirá garantizar que los escenarios, macroeconómico y de ingresos y gastos, están sirviendo para la finalidad que fueron elaborados y que se posee la capacidad de reacción suficiente para actuar respecto de las desviaciones.

Este instrumento se caracteriza por:

- Elaborar estimaciones realistas de ingresos y gastos.

- Planear estratégicamente en un periodo mayor a los 12 meses (es decir de 3 a 5 años).

- Complementar con el presupuesto anual de carácter obligatorio.

- Gestionar por objetivos.

- Tener una activa participación de los ejecutores de gastos en las etapas de formulación y aprobación. 
FIGURA 5

\section{ELEMENTOS DEL PRESUPUESTO PLURIANUAL}

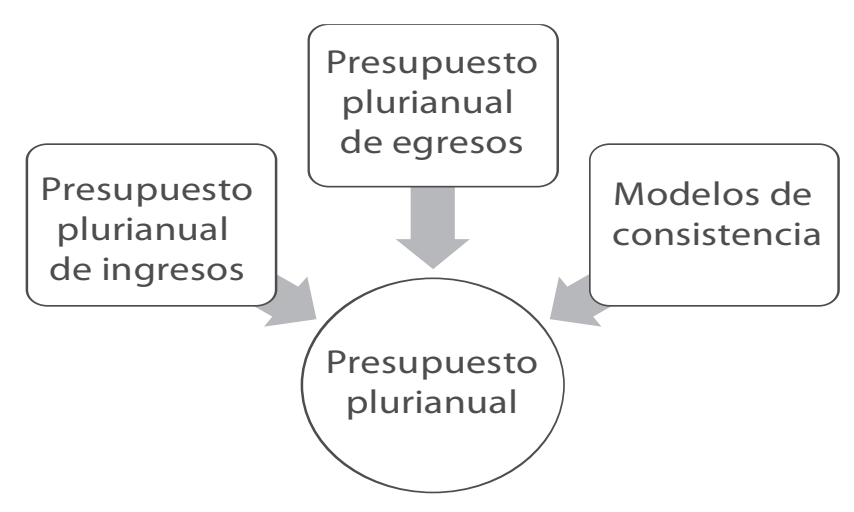

Fuente: Elaboración propia

- Asignar gastos en el marco de prioridades nacionales y sectoriales (que va de arriba hacia abajo) esto hace la diferencia al Presupuesto Plurianual de las Proyecciones Presupuestarias.

- Evaluar por Resultados

- Orientar las políticas públicas.

Nótese que estamos ante una labor más compleja y detallada que la elaboración del presupuesto tradicional e inclusivo que otras formas de presupuestación más completas como presupuesto por programas o por resultados; ahora bien, ello se justifica dadas los beneficios que posee para la adecuada gestión de las finanzas públicas.

\section{Beneficios de esta forma de presupuestación}

El presupuesto plurianual posee beneficios tanto a nivel macroeconómico como microeconómico.

En el ámbito macroeconómico le permite a las autoridades políticas conocer, evaluar y corregir el comportamiento fiscal de los países más allá de la coyuntura económica actual o del año en curso, por lo que puede ser utilizado como un freno a la toma de decisiones sobre gastos sin financiamiento o medidas que alteran negativamente el resultado fiscal y que podrían a futuro poner en riesgo la sanidad de las finanzas públicas.

Igualmente, atenúa la rigidez de la estructura de gastos, permitiendo la reorientación de los ahorros producidos por la finalización de programas y proyectos e incrementa la capacidad de control global y particular del gasto; lo cual permite reducir la incertidumbre del sector privado sobre el comportamiento futuro de las cuentas públicas.

Por otro lado en el aspecto microeconómico el facilita el seguimiento y cumplimiento de los programas y proyectos de maduración plurianual. Contribuye a reducir la incertidumbre de los Organismos y Entidades Públicas respecto a las asignaciones de mediano plazo y se adecua mejor que el PGN al proceso de gestión pública orientada a resultados; y finalmente incentiva la práctica del planeamiento estratégico de los Organismos y Entidades del Estado.

En síntesis los beneficios de este instrumento se pueden enlistar de la siguiente manera: 
- Estimula a las autoridades a pensar en el mediano plazo.

- Introduce la planeación estratégica y un enfoque basado en resultados.

- Mejora la planificación a largo plazo.

- Incrementa la previsibilidad del gasto público.

- Reduce la incertidumbre del sector privado sobre el comportamiento futuro de las cuentas públicas.

- Crea un buen clima de negocios a través del refuerzo de disciplina fiscal y la gobernabilidad Conoce, evalúa y de ser posible corrige el comportamiento fiscal de los Estados.

- $\quad$ Fortalece la gestión del rendimiento.

- Reorienta los ahorros que se generan en el futuro y canalizarlos hacia las prioridades del gobierno.

- Facilita el seguimiento y cumplimiento de los proyectos y programas de maduración plurianual

Por otro lado, aun cuando se ha hecho énfasis en sus beneficios también es preciso indagar acerca de sus limitaciones para considerarlas al momento de implementar este instrumento.

Como obstáculo se podría señalar la necesaria participación activa de toda la organización lo cual no siempre es posible de lograr.

Posee la desventaja de que en un contexto político, institucional e inflacionario inestable se puede desactualizar con rapidez por la dificultad de realizar previsiones adecuadas, por lo que un clima de incertidumbre económica puede convertirse en un obstáculo.

Dado que se base en proyecciones econométricas estas de manera inherente poseen limitaciones dada la dificultad para proyectar los ingresos por más de un año.

Finalmente, se requiere una actitud realista, si bien, contribuye a la sanidad de las finanzas públicas requiere de otras muchas acciones estatales para lograrlo, y no resulta por sí misma una panacea para las deficiencias de los presupuestos tradicionales, algunos gobiernos u organizaciones que implementaron esta presupuestación han reportado mejoras significativas mientras que otros no puedes para ser efectivo requiere de otras decisiones gubernamentales en otras áreas de la economía nacional.

\section{La presupuestación plurianual en el mundo}

El Banco Mundial desde hace varios años ha señalado que los fallos de coordinación entre política económica, planificación y presupuesto constituyen la principal causa de los fracasos en las medidas de política presupuestaria, y ha recomendado el establecimiento de marcos presupuestarios a medio plazo, en lugar del tradicional presupuesto anual como una manera para realizar una mejor coordinación y gestión de las finanzas públicas.

Destaca el aporte de la presupuestación plurianual a la falta de adecuación entre política económica y presupuesto, y su carácter de instrumento para solventar otros problemas que en el aspecto de la planificación se les presentan a los gobiernos.

Este instrumento ha sido implementado por varios países en todo el mundo, incluso se podría afirmar que todos los países desarrollados, dentro de ellos podemos citar los que se muestran en la Tabla 1. 
TABLA 1

PAÍSES CON PRESUPUESTO PLURIANUAL

\begin{tabular}{|l|l|}
\hline Continente & $\begin{array}{l}\text { Países con presupuesto } \\
\text { plurianual }\end{array}$ \\
\hline América & $\begin{array}{l}\text { Argentina, Brasil, Canadá, Colombia, Chile, Estados } \\
\text { Unidos, Guatemala, Paraguay y Uruguay }\end{array}$ \\
\hline Europa & $\begin{array}{l}\text { Alemania, Bélgica, Francia, Holanda, Irlanda, Italia, } \\
\text { Noruega, Reino Unido, Suecia y todos los países } \\
\text { desarrollados de Europa }\end{array}$ \\
\hline África & Kenya, Marruecos, Sudáfrica \\
\hline Asia & Indonesia, Israel, Japón, Korea \\
\hline Ocenia & Australia, Nueva Zelanda \\
\hline
\end{tabular}

Fuente: elaboración propia.

Interesa estudiar las experiencias de los países en América Latina que poseen similitud con nuestro país, tales como:

\section{a. Uruguay}

El primer país en América Latina en implementar la presupuestación plurianual dado que la incluyó en su legislación desde los años 70. En Uruguay el presupuesto nacional se aprueba para un periodo de cinco años, coincidiendo con la duración de cada legislatura. El presupuesto quinquenal recoge el presupuesto en vigor cuando se accede al gobierno y el presupuesto base para los cuatro años siguientes. Cada año se pueden introducir actualizaciones, pero el periodo de vigencia del presupuesto no se amplía, permanece fijo. El momento de introducir estos cambios coinciden con la rendición de cuentas del ejercicio anterior: se presentan ajustes al presupuesto en curso que pueden extenderse a los años restantes de vigencia del presupuesto.

Estos ajustes están limitados por los objetivos fiscales del gobierno y corresponden fundamentalmente con las actualizaciones monetarias. Las Cámaras en el trámite parlamentario también pueden modificar los presupuestos anualmente, aunque los cambios no son sustanciales cuantitativamente.

El proceso presupuestario quinquenal comienza con la elaboración de parte del Ministerio de Economía y Finanzas (MEF) de las previsiones macroeconómicas y la determinación del espacio fiscal. Este margen se distribuye entre las áreas de gasto atendiendo a las prioridades estratégicas y a los objetivos de política del gobierno. Participan dos instituciones en la elaboración del presupuesto: el MEF, que elabora el presupuesto de gastos de personal y gastos corrientes, y la Oficina de Planeamiento y Presupuesto, que elabora el presupuesto de inversión.

Una vez aprobado el presupuesto y además de los ajustes anuales, a lo largo del ejercicio el Poder Ejecutivo puede realizar modificaciones presupuestarias: transferencias entre créditos y ampliaciones con ciertas limitaciones legales. También en caso de acontecimientos graves o imprevistos. Las previsiones macroeconómicas que soportan el proyecto del presupuesto quinquenal se publican en el momento de aprobación del presupuesto, pero no se actualizan en las modificaciones anuales.

\section{b. Colombia}

La Constitución Política Colombiana incluye el presupuesto plurianual en concordancia con el Plan Nacional de Desarrollo, dada la íntima relación que existe entre plan-presupuesto, al respecto dice:

Artículo 339. Habrá un Plan Nacional de Desarrollo conformado por una parte general y un plan de inversiones de las entidades públicas del orden nacional. En la parte general se señalarán los propósitos y objetivos nacionales de largo plazo, las metas y prioridades de la acción estatal a mediano plazo y las estrategias y orientaciones generales de la política económica, social y ambiental que serán adoptadas por el gobierno. El 
plan de inversiones públicas contendrá los presupuestos plurianuales de los principales programas y proyectos de inversión pública nacional y la especificación de los recursos financieros requeridos para su ejecución. Las entidades territoriales elaborarán y adoptarán de manera concertada entre ellas y el gobierno nacional, planes de desarrollo, con el objeto de asegurar el uso eficiente de sus recursos y el desempeño adecuado de las funciones que les hayan sido asignadas por la Constitución y la ley. Los planes de las entidades territoriales estarán conformados por una parte estratégica y un plan de inversiones de mediano y corto plazo (Ministerio de Hacienda, 2012).

Desde el año 2006 éste país ha realizado esfuerzos para consolidar un proceso de programación del presupuesto anual enfocado en el mediano plazo y organizado bajo un esquema sectorial, que busca promover una discusión amplia, estratégica y disciplinada entre las autoridades de presupuesto y planeación y los diferentes sectores involucrados.

Asimismo en el 2005 se aprobó el Decreto 4730 mediante el cual se implementó el Marco de Gasto de Mediano Plazo (MGMP), el cual ha permitido construir un escenario más predecible para la asignación y ejecución de los recursos públicos, al hacer explícitos los efectos y restricciones que las decisiones de gasto anual pueden tener en el futuro. El MGMP se aprueba para un periodo cuatrienal y constituye un punto de referencia de los sectores sobre los recursos presupuestales con los que podrían contar en los años siguientes al del proyecto de presupuesto si no se presentan cambios en la coyuntura económica, política o social.

Se formula con base en la propuesta presupuestal de mediano plazo (PMP) concertada entre el sector y las autoridades presupuestales, un ejercicio de proyecciones que se revisa anualmente.
De esta forma, el MGMP facilita en gran medida el desarrollo de una gestión más eficiente y efectiva, consistente entre las necesidades sectoriales y las posibilidades fiscales.

c. Brasil

El artículo 165 de la Constitución Federal de la República de Brasil demanda que la presupuestación en ese país deberá ser plurianual con proyecciones a 4 años que corresponde al mandato presidencial, textualmente dice:

Seção II

\section{Dos Orçamentos}

Art. 165. Leis de iniciativa do Poder Executivo estabelecerão:

I - o plano plurianual;

II - as diretrizes orçamentárias;

III - os orçamentos anuais.

$\S 1 \circ$ A lei que instituir o plano plurianual estabelecerá, de forma regionalizada, as diretrizes, objetivos e metas da administração pública federal para as despesas de capital e outras delas decorrentes e para as relativas aos programas de duração continuada.

$\S 2 \circ$ A lei de diretrizes orçamentárias compreenderá as metas e prioridades da administração pública federal, incluindo as despesas de capital para o exercício financeiro subseqüente, orientará a elaboração da lei orçamentária anual, disporá sobre as alterações na legislação tributária e estabelecerá a política de aplicação das agências financeiras oficiais de fomento.

$\S 3^{\circ} \mathrm{O}$ Poder Executivo publicará, até trinta dias após o encerramento de cada bimestre, 
relatório resumido da execução orçamentária.

$\S 4^{\circ}$ Os planos e programas nacionais, regionais e setoriais previstos nesta Constituição serão elaborados em consonância com o plano plurianual e apreciados pelo Congresso Nacional.

$\S 5^{\circ}$ A lei orçamentária anual compreenderá:

I - o orçamento fiscal referente aos Poderes da União, seus fundos, órgãos e entidades da administração direta e indireta, inclusive fundações instituídas e mantidas pelo poder público;

II - o orçamento de investimento das empresas em que a União, direta ou indiretamente, detenha a maioria do capital social com direito a voto;

III - o orçamento da seguridade social, abrangendo todas as entidades e órgãos a ela vinculados, da administração direta ou indireta, bem como os fundos e fundações instituídos e mantidos pelo poder público.

§ $6^{\circ} \mathrm{O}$ projeto de lei orçamentária será acompanhado de demonstrativo regionalizado do efeito, sobre as receitas e despesas, decorrente de isenções, anistias, remissões, subsídios e benefícios de natureza financeira, tributária e creditícia.

$\S 70$ Os orçamentos previstos no $\S 50$, I e II, deste artigo, compatibilizados com o plano plurianual, terão entre suas funções a de reduzir desigualdades inter-regionais, segundo critério populacional.

§ $8 \circ$ A lei orçamentária anual não conterá dispositivo estranho à previsão da receita e à fixação da despesa, não se incluindo na proibição a autorização para abertura de créditos suplementares e contratação de operações de crédito, ainda que por antecipação de receita, nos termos da lei.

$\S 9^{\circ}$ Cabe à lei complementar:

I - dispor sobre o exercício financeiro, a vigência, os prazos, a elaboração e a organização do plano plurianual, da lei de diretrizes orçamentárias e da lei orçamentária anual;

1 - estabelecer normas de gestão financeira e patrimonial da administração direta e indireta, bem como condições para a instituição e funcionamento de fundos. (Assembléia Nacional Constituinte, 1988)².

El presupuesto plurianual juntamente con la Ley Directrices presupuestarias y la Ley de Presupuesto Anual establecen en conjunto las metas y prioridades de la Administración Pública Federal, su funcionamiento se explica de la siguiente forma:

Plano Plurianual (PPA) Lei de Diretrizes Orçamentárias (LDO) Lei Orçamentária Anual (LOA)

O PPA, juntamente com a LDO e a LOA são leis instituídas pela Constituição Federal - art. 165. A LDO, que deve ser compatível com o PPA, estabelece, entre outros, o conjunto de metas e prioridades da Administração Pública Federal e orienta a elaboração da LOA para o ano seguinte. A LOA contempla os orçamentos fiscal, da seguridade social e de investimentos das estatais. O seu vínculo com o PPA se dá por meio dos Programas e das Iniciativas do Plano que estão associadas às Ações constantes da LOA. Deve haver, portanto, uma compatibilidade entre o PPA, 
a LDO e a LOA. Contudo, vale ressaltar que a abrangência do PPA e da LDO vai além da dimensão orçamentária. A proposta de Plano Plurianual deve ser elaborada pelo Poder Executivo durante o primeiro ano de mandato do Presidente da República e, após a votação no Congresso e a sanção presidencial, o Plano deve orientar a ação de governo. (Governo do Brasil, 2015)3.

El gobierno destaca la contribución de esta forma de presupuestación para la transparencia y rendición de cuentas, al respecto señala:

O PPA serve para orientar o Estado e a sociedade no sentido de viabilizar os objetivos da República. Para tanto, ele apresenta a visão de futuro para o Brasil, macrodesafios e valores que guiam o comportamento para o conjunto da Administração Pública Federal, além de informar as metas do Estado para o período de 4 anos com os respectivos arranjos para a implementação. Dessa forma, o PPA contribui para revelar e organizar a ação de governo na busca de um melhor desempenho da Administração Pública. O

2. Traducción propia. Sección II. De los presupuestos. Art. 165: Las leyes de iniciativa del Poder Ejecutivo establecerá: I - el plan plurianual; II - las directrices presupuestarias; III - los presupuestos anuales. 1. La ley que instituye el plan plurianual establecerá, con carácter regionalizada las directrices, objetivos y metas de la administración pública federal para los gastos de capital y otros derivados de ellos y para las relativas a los programas continuos. 2. La ley de directrices presupuestarias comprenderá las metas y prioridades de la administración pública federal, incluyendo los gastos de capital para el año fiscal subsiguiente, orientará la preparación de la ley de presupuesto anual, dispondrá sobre las modificaciones a la legislación tributaria y establecerá la política de aplicación de las agencias financieras oficiales de financiación del desarrollo. $3 \mathrm{El}$ Poder Ejecutivo publicará, dentro de los treinta días siguientes al final de cada bimestre, un el informe de síntesis sobre la ejecución del presupuesto. 4 Los planes y programas nacionales, regionales y sectoriales establecidas en esta Constitución serán preparados de acuerdo con el plan plurianual y examinados por el Congreso Nacional. 5. La ley de presupuesto anual deberá incluir: I - el presupuesto fiscal refiriéndose a los Poderes de la Unión, sus fondos, organismos y entidades de la administración directa e indirecta, incluidas las fundaciones instituidas y mantenidas por el Gobierno; II - el presupuesto de inversión de las empresas en las que la Unión
PPA: 1) permite à sociedade confirmar que o governo está cumprindo os compromissos firmados na eleição; 2) serve para o governo declarar e organizar sua atuação, a fim de entregar o produto certo, no local certo, na hora certa. (Governo do Brasil, 2015) ${ }^{4}$.

d. Chile

Chile cuenta con un marco fiscal de mediano plazo (MFMP) que abarcando proyecciones a nivel agregado de gasto y no sectoriales. Se publicó por primera vez en 2002, aunque ya se venía elaborando con anterioridad.

La proyección financiera del Gobierno Centra cuantifica la evolución previsible de sus ingresos y gastos a partir de: 1) La legislación vigente sobre impuestos y seguridad social, 2) Obligaciones de gastos, 3) Perspectivas macroeconómicas y 4) Compromisos de política vigente.

Se realiza una proyección macroeconómica, que no implica asignaciones de recursos a actividades específicas; es decir, su objetivo se centra en la determinación de las disponibilidades netas de recursos a partir de la comparación de las

directa o indirectamente ostenta la mayoría de las acciones con derecho a voto; III - el presupuesto de la seguridad social, abarca todas las entidades y organismos vinculados a la misma, la administración directa o indirecta, así como los fondos y fundaciones instituidas y mantenidas por el gobierno. 6. El proyecto de ley de presupuesto se acompañará de una declaración de efecto regionalizado sobre los ingresos y gastos, derivados de exenciones, amnistías, condonaciones, subsidios y beneficios de naturaleza financiera, fiscal y de crédito.7. Los presupuestos previstos en el numeral 5, I y || de este artículo, emparejados con el plan plurianual, tendrá entre sus funciones la de reducir las desigualdades interregionales, siguiendo criterios poblacionales. 8 La ley de presupuesto anual no contendrá ninguna prestación ajena a una previsión de los ingresos y una fijación de los gastos, no se incluirá la prohibición a la autorización para la apertura de créditos complementarios y contratación de operaciones de crédito, aún por adelanto de impuestos, en los términos de la ley. 9. Una ley complementaria: I - Dispondrá sobre el ejercicio financiero, la vigencia, los plazos, la preparación y organización del plan plurianual, de la ley de directrices presupuestarias y la ley de presupuesto anua|; II - establecer normas de gestión financiera y patrimonial de la administración directa e indirecta, así como las condiciones para la institución y el funcionamiento de los fondos. 
proyecciones de ingresos, los compromisos de gastos y los límites impuestos por la política fiscal, por lo que se puede notar es una forma diferente al resto de países pero que resulta acorde con la normativa y necesidades de éste país.

\section{e. Paraguay}

La confección del Presupuesto Plurianual se inserta en el sistema de programación presupuestaria de Paraguay bajo el principio de planificación integral introducido en el país por el artículo 11 de la Ley No 1535/1999 "De Administración Financiera" y se reglamenta por el Artículo 25 del Decreto No 8.127 del 30/03/2000, que sostiene que el presupuesto de los Organismos y Entidades del Estado refleja los planes de acción, los objetivos y las metas, de corto, mediano y largo plazo fijados en los planes de desarrollo aprobados por el Gobierno Nacional.

A estos efectos, la Secretaría Técnica de Planificación de la Presidencia de la República, en su carácter de organismo rector del sistema de planificación gubernamental ha desarrollado Líneas Estratégicas del Desarrollo que constituyen la guía para el accionar de las instituciones públicas en el mediano y largo plazo. Se trata del marco orientador para la elaboración de los planes sectoriales de estas instituciones, así como

3. Traducción propia. Plan Plurianual (PPA) Ley de Directrices Presupuestarias (LDO) Ley de Presupuesto Anual (LOA) La PPA juntamente con la LDO y la LOA son leyes instituidas por la Constitución Federal - art. 165. La LDO, que debe ser compatible con el PPA establece, entre otros, el conjunto de metas y prioridades del gobierno federal y orienta la elaboración de la LOA para el año siguiente. La carta LOA los presupuestos fiscales, de seguridad social y de inversiones estatales. Su relación con el PPA se da por medio de los programas y las iniciativas del plan que están asociadas a las acciones constantes de la LOA. Por lo tanto, debe existir una compatibilidad entre el PPA, la LDO y la LOA. Sin embargo, cabe destacar que el alcance de la PPA y la LDO van más allá de la dimensión presupuestaria. La propuesta de Plan Plurianual debe ser elaborado por el Poder Ejecutivo durante el primer año de su mandato presidencial, y después de la votación en el Congreso y la sanción presidencial, el Plan debe guiar y orientar el actuar del gobierno. también de los planes operativos anuales y de la presupuestación.

Complementariamente, las normas de la Ley $\mathrm{N}^{\circ}$ 1535/1999 establecen la necesidad de que los anteproyectos y proyectos de presupuesto de los Organismos y Entidades del Estado deben ser compatibles con los planes operativos institucionales (Artículo 15). De acuerdo con lo desarrollado por la Secretaría los planes operativos anuales tienen el propósito de que las acciones ejecutadas por cada institución del Sector Público sean conducidas en forma eficiente a la consecución de sus objetivos, dentro de tiempos y plazos predeterminados.

f. Perú

El gobierno peruano elabora un Marco Macroeconómico Plurianual a 3 años, que incorpora la ejecución del ejercicio anterior, el año correspondiente al presupuesto y dos posteriores en términos de clasificación económica.

Ello permite verificar el cumplimiento de las restricciones fiscales e incorporar un análisis de la dinámica de la deuda pública. Corresponde a una base rodante, pues cada año incorpora o avanza un ejercicio. Incluye las orientaciones de política económica y los objetivos presupuestarios; cada año se aprueba en mayo por el Consejo de Ministros y el presupuesto que se presenta en agosto debe ser coherente con los objetivos fjados en ese escenario. Se elaboran también planes plurianuales de inversión pública.

4. El PPA sirve para guiar el Estado y la sociedad en el sentido de habilitar los objetivos de la República. Por lo tanto, presenta una visión del futuro de Brasil, macrodesafios y valores que guían el comportamiento de toda la Administración Pública Federal, además de informar las metas del Estado para el período de 4 años con los respectivos ajustes para su desarrollo. De esta forma, el PPA contribuye a revelar y organizar el accionar del gobierno en la búsqueda de un mejor funcionamiento de la administración pública. La PPA: 1) permite a la sociedad confirmar que el gobierno está cumpliendo con los compromisos asumidos en la campaña electoral; 2) Sirve para que el gobiemo declare y organice su actuación, con el fin de entregar el producto correcto, en el lugar correcto y en el momento adecuado. 


\section{g. México}

El presupuesto mexicano presenta un marco macroeconómico que cubre 10 años: cinco años anteriores al proyecto y cinco años posteriores, el cual incluye proyecciones económicas de las variables clave: el PIB, la inflación, la tasa de interés nominal y la cuenta corriente de los próximos cinco años; así como un panorama general de las finanzas públicas.

Estas proyecciones se centran en dos elementos relevantes: la trayectoria esperada del precio del petróleo y, las presiones de gasto sobre las necesidades de endeudamiento. Las proyecciones a 10 años son a nivel agregado e incluyen gastos de personal, pensiones, subsidios y transferencias, gasto de capital y otras operaciones.

También se presentan estimaciones de las transferencias a los gobiernos subnacionales y pagos por aportaciones a la seguridad social y a los servicios de salud como porcentaje del PIB. Se consideran igualmente las estimaciones del saldo presupuestario primario y de la evolución de la deuda neta del sector público.

Nótese que aun cuando varios países en América Latina utilizan el mismo concepto de presupuesto plurianual la forma de elaborarlo difiere en cada uno, pues no existe homogeneidad en este aspecto, sino que cada gobierno lo ajusta según sus capacidades y realidad económica.

\section{Propuesta para implementar la planificación plurianual en Costa Rica}

La Contraloría General de la República en sus informes de labores presentados ante la Asamblea Legislativa ha reiterado su preocupación por la inestabilidad de las finanzas públicas y el riesgo que ello conlleva para el futuro del país.

Al respecto ha señalado que existe un desequilibrio financiero estructural y un riesgo de insolvencia en el sector público costarricense que se viene manifestando, principalmente, en el Presupuesto de la República, con mayor intensidad a partir del 2009 a la fecha, con una tendencia de déficit promedio de $4,6 \%$ del PIB, Io cual influye en la actual capacidad de gestión del Gobierno, con el agravante de que incluso el déficit primario (sin considerar el gasto por intereses) supera ya un 3\% del PIB (indicador del ajuste fiscal necesario solo para que la deuda no siga creciendo). La carga tributaria (relación de los ingresos tributarios con el producto interno bruto), que había crecido ininterrumpidamente desde el año 2000 hasta el 2008, pasa a ubicarse en un 15.34\% en ese año, disminuye posteriormente, ubicándose en un cifra cercana al 13.3\% durante los años 2009-2013.

Precisamente, con la finalidad de aportar e incidir de manera decidida en la mejora y fortalecimiento de esas condiciones actuales se propone el proyecto de ley denominado "Adición de un párrafo primero y reforma del tercer párrafo del artículo 176 de la Constitución Política de la República de Costa Rica (Principios de sostenibilidad fiscal y plurianualidad)" que aspira a instituir como norma suprema y, por ende, con el mayor rango posible, dos principios esenciales a ser observados por la Administración Pública en su gestión de la hacienda pública: la necesaria sostenibilidad fiscal, la que en todo caso debe conducirse de manera transparente y responsable y la presupuestación plurianual como instrumento primordial para la realización de la primera.

Dicho proyecto destaca de la siguiente forma la plurianualidad en la administración de las finanzas públicas:

Uno de los principales instrumentos para la obtención de la sostenibilidad fiscal aludida lo constituye la "plurianualidad", materializada en planes y presupuestos referenciales que permiten y facilitan la distribución de los recursos financieros de las instituciones 
públicas en un periodo mayor al anual. Esto no demerita el principio presupuestario de anualidad, actualmente recogido en la Constitución Política y en la Ley de la Administración Financiera y de Presupuestos Públicos, sino que más bien lo complementa y fortalece. De tal manera que se consideran los ingresos y gastos acordes con marcos fiscales de mediano plazo para el Sector Público y proyecciones de la gestión financiera de cada institución, con el objetivo de lograr resultados definidos o pretendidos en la planificación de mediano y largo plazo y la estabilidad financiera institucional. (Contraloría General de la República, 2015, págs. 4-5)

Asimismo, el proyecto resalta el aporte del presupuesto plurianual para lograr la sostenibilidad fiscal del país y de las instituciones que integran el gobierno, señalando los siguientes puntos:

- Corrección de comportamientos fiscales. El Presupuesto Plurianual estimula a las autoridades política a conocer, evaluar y -de ser necesario-corregir el comportamiento fiscal, más allá de la coyuntura anual y constituye un incentivo o estímulo para pensar en los motivos que causan problemas y en las formas de resolverlas. Por ejemplo, si no se desea la morosidad crónica, resulta oportuno contar con mecanismos que faciliten la programación de los recursos públicos para evitar nuevos gastos antes de que éstos sean irreversibles. Por otra parte, permite vislumbrar e identificar tendencias con el suficiente tiempo como para tomar medidas preventivas en forma temprana y oportuna. En ese sentido, se constituye en un límite a medidas con efectos fiscales negativos. Esta herramienta permitirá establecer como regla general que, entre otros, toda iniciativa con relación a la gestión de las remuneraciones, los gastos operativos, los proyectos de inversión, los contratos, los convenios o las medidas con impacto en presupuestos futuros, entre otros, deben estar dentro del marco fiscal de mediano plazo. De esta manera, se está mejor preparado para administrar situaciones o casos que comprometen gastos futuros, en vista de que la anualidad del presupuesto por sí sola ha sido insuficiente para resolver la viabilidad de una serie de casos que son habituales en la realidad de la Administración Pública.

- Incremento de la flexibilidad en la asignación de recursos. Este instrumento atenúa la rigidez de la estructura de costos y gastos, permitiendo la reorientación de los ahorros producidos por la finalización de programas y proyectos. En una estructura de gasto público con alto porcentaje de rigidez, el enfoque plurianual amplía el reducido margen de discrecionalidad asignada que se tiene con el presupuesto anual. En un horizonte de mediano plazo, hay programas o proyectos que terminan, disposiciones que cumplen con su cometido, generación de ahorros o reducción de costos y gastos por la aplicación de nuevos métodos o procedimientos más eficientes, que liberan recursos que pueden ser reorientados para otros fines.

- Otras razones que para implementar esta herramienta se encuentran en el incremento de la capacidad de control global y particular del gasto, la mejora en el seguimiento y cumplimiento de programas y proyectos mayores a un año, una mejor orientación a resultados y un mayor incentivo al planeamiento estratégico de cada institución. (Contraloría General de la República, 2015, pp. 5-6)

Para alcanzar este objetivo el texto propone una modificación del artículo constitucional 176 para que en adelante se redacte de la siguiente forma: 
Artículo 176.- La gestión pública se conducirá de forma sostenible, transparente y responsable, la cual se basará en un marco de presupuestación plurianual, en procura de la continuidad de los servicios que presta.

El presupuesto ordinario de la República comprende todos los ingresos probables y todos los gastos autorizados de la administración pública, durante todo el año económico. En ningún caso el monto de los gastos podrá exceder el de los ingresos probables.

La administración pública en sentido amplio observará las reglas anteriores para dictar sus presupuestos.

El presupuesto de la República se emitirá para el término de un año, del primero de enero al treinta y uno de diciembre. (Contraloría General de la República, 2015, pp. 13-14)

El presente proyecto ha recibido una buena acogida entre los diputados pero está en corriente legislativa.

\section{CONCLUSIONES}

Existe coincidencia entre diferentes sectores del aporte del presupuesto plurianual para la sanidad y estabilidad de las finanzas públicas dado que obliga a los Estados a planificar más allá de un año, sino que debería programar desde la toma de posición cuáles son las acciones que integran su plan de gobierno y deberá planificar desde el inicio la manera en la cual alcanzará los objetivos y metas propuestos en la campaña electoral.

Dada la preocupación por la inestabilidad futura de nuestras finanzas públicas y estabilidad económica del país se está proponiendo modificar la manera actual en la cual se elabora el presupuesto para emigrar a la presupuestación plurianual con el objetivo que permite tener una mayor claridad de los ingresos y gastos del Estado tanto en el corto como en el mediano plazo.

Ahora bien, aun cuando este instrumento da un gran aporte para la planificación y sanidad de las finanzas públicas no puede considerarse la panacea que instantáneamente resuelva los problemas, sino que debe verse como un instrumento más dentro del abanico de acciones que debe implementar el Estado para la correcta gestión de los fondos públicos. De tal manera, que debe tomarse como un adecuado instrumento pero siendo consciente que existen muchas acciones más que se deben implementar paralelamente para lograr la estabilidad de los fondos públicos.

\section{REFERENCIAS}

Arroyo Chacón, J. I. (2012). La aprobación presupuestaria como un instrumento de control previo ejercido por la Contraloría General de la República de Costa Rica sobre la Hacienda Pública. Revista do Tribunal de Contas do Estado de Minais Gerais do Brasil, 94-100.

Arroyo Chacón, J. I., \& Bolaños González, J. (2012). Derecho Empresarial II. San José, Costa Rica : Editorial EUNED.

Asamblea Legislativa. (1994). Ley Nº 7428 denominada Ley Orgánica de la Contraloría General de la República. San José, Costa Rica: Asamblea Legislativa.

Asamblea Legislativa. (2009). Ley Nº 6227 denominada Ley General de la Administración Pública . San José, Costa Rica: SINALEVI.

Assembléia Nacional Constituinte. (1988). Constituição da República Federativa do Brasil. Brasil: Recuperado de: http://www.senado.gov.br/legislacao/const/con1988/CON1988_05.10.1988/ CON1 988.shtm.

Contraloría General de la República. (2012). Normas técnicas sobre presupuestos públicos N-1-2012-DCDFOE. San José, Costa Rica: Contraloría General de la República. 
vvpública. (2015). Memoria Anual 2014. San José, Costa Rica: Contraloría General de la República.

Contraloría General de la República. (2015). Presupuestos Públicos 2015: Situación y Perspectivas. San José, Costa Rica : Contraloría General de la República.

Contraloría General de la República. (2015). Proyecto de ley Adición de un párrafo primero y reforma del tercer párrafo del artículo 176 de la Constitución Política de la República de Costa Rica (Principios de sostenibilidad fiscal y plurianualidad). San José Costa Rica : Asamblea Legislativa .

Governo do Brasil. (2015, Julio ). Ministério do Planejamento. From Planejamento Governamental: http://antigo.planejamento.gov.br/editoria.asp? $p=$ editoria\&inde $=62 \&$ ler $=s 676$

International Monetary Fund. (2015). Costa Rica - Selected Issues and Analytical Notes. Washington: Disponible en http://www.imf.org/external/ pubs/ft/scr/2015/cr1530.pdf.

International Monetary Fund. (2015). Staff Report for the 2014 Article IV Consultation. Washington: Disponible en http://www.imf.org/external/pubs/ $\mathrm{ft} / \mathrm{scr} / 2015 / \mathrm{cr} 1529 . p d f$.

Ministerio de Hacienda. (2003). Decreto No. 31458-H denominado Clasificador de Ingresos. San José, Costa Rica: Gaceta 223.

Ministerio de Hacienda. (2004). Decreto No. 31877-H denominado Clasificador Económico del Gasto. San José, Costa Rica: Gaceta 14019.

Ministerio de Hacienda. (2007). Decreto No. 33875-H denominado Clasificador Funcional. San José, Costa Rica: Gaceta 126.
Ministerio de Hacienda. (2008). Decreto No. 34325-H denominado Clasificador de objeto del gasto. San José, Costa Rica : Gaceta 38.

Ministerio de Hacienda. (2012). Aspectos generales de las etapas del ciclo presupuestal de los órganos que conforman el presupuesto general de la Nación. Colombia. Recuperado de: http://www. minhacienda.gov.co/portal/page/portal/HomeMinhacienda/presupuestogeneraldelanacion/ AnteproyectoPGN/2011/2-\%20ASPECTOS\%20 GENERALES\%20ETAPAS\%20PROCESO\%20PRESUPUESTAL\%20NACION.pdf.

Pi, A. (2008). Implementación del Presupuesto Plurianual en Paraguay. Paraguay: Curso de Postgrado Especialización en Administración y Control Gubernamental - CEMAF/UNI A.

Quintana , J. I., \& Palancar Valera, J. M. (2012). Presupuestación y Técnicas Presupuestarias. In Maestría Internacional en Hacienda Pública y Administración Financiera. Madrid, España: UNED-CEDDET.

Sastre Torregrosa, E. (2014). Experiencia y tendencias internacionales en presupuesto público y estructuras presupuestarias: Análisis para Colombia. Colombia. Recuperado de: http://www.minhacienda. gov.co/portal/page/portal/HomeMinhacienda/ asistenciaentidadesterritoriales/Publicaciones/ Libros/Informe\%20Colombia\%2019\%2002\%20 2014.pdf.
Recibido: 22 de julio de 2015 Aceptado: 10 de febrero de 2016 
This document was created with Win2PDF available at http://www.win2pdf.com. The unregistered version of Win2PDF is for evaluation or non-commercial use only. This page will not be added after purchasing Win2PDF. 